\title{
Resource depression in Daphnia galeata, Daphnia cucullata and their interspecific hybrid: life history consequences
}

\author{
Maarten Boersma and Jacobus Vijverberg \\ Netherlands Institute of Ecology, Centre for Limnology, Rijksstraatweg 6, 3631 \\ AC Nieuwersluis, The Netherlands (e-mail: boersma@nioo.nl)
}

\begin{abstract}
In this study, the effect of the food concentration on several life history parameters of Daphnia galeata, Daphnia cucullata and the hybrid between these two species was examined. The food concentration had a significant effect on both growth and reproduction of all three taxa. Mortality was highly species specific, and to a lesser extent dependent on the food concentration. Changes in life history parameters resulted in changes in the intrinsic rate of population increase $(r)$. The food dependence of the different species was found to be different. Daphnia cucullata had a relatively constant and low $r$. The $r$ values for the hybrid varied most, with low values compared with the parental species when grown at low food levels and relatively high values at higher food concentrations. Our results suggest that when food concentrations are high the hybrid will have a selective advantage over both parental species, but that at lower food levels $D$.galeata will have an advantage over both D.cucullata and the hybrid.
\end{abstract}

\section{Introduction}

The relative influence of predation and food limitation as factors regulating the seasonal dynamics of cladoceran zooplankton is the subject of an ongoing debate (e.g. Gliwicz, 1985; Lampert, 1988; Luecke et al., 1990). Recent work has shown that both factors may play a role, but that their relative importance may vary seasonally (e.g. Gliwicz and Pijanowska, 1989). Predation by fish is most likely to be important later in the season when high numbers of juvenile fish are present (Luecke et al., 1990; Boersma et al., 1991). Food limitation is probably important during larger parts of the growing season (e.g. Gliwicz, 1985; Lampert et al., 1986; Luecke et al., 1990), and it is likely to be especially severe in early summer, during the clear-water phase (e.g. Larsson et al., 1985). From our own research in Tjeukemeer (Boersma and Vijverberg, 1994c), we concluded that Daphnia species are food limited the whole year round, except for an $\sim 2$-month period in spring. The severest food limitation was found in mid-summer. Thus, since food limitations are obviously important under natural circumstances, we will present data on the effect of different food concentrations on selected life history parameters of two species within the Daphnia longispina group: Daphnia galeata and Daphnia cucullata, and of their hybrid. In our study lake, Tjeukemeer, these three taxa occur together during large parts of the year in different relative densities to one another. Although there is some evidence that hybridization between the species is an ongoing process (Schwenk, 1993), we will treat the hybrids here as a distinct species. Variations in food concentrations may directly affect individual growth rates, size of the individuals at first reproduction, reproductive output and the mortality rates. The size of the animals is an important factor in the ecology of the species, as it is directly related to the vulnerability of the animals to predation. Consequently, we will 
focus on growth and the resulting size at first reproduction. Attention will also be paid to the effect of different food concentrations on reproduction, since this is another important factor in determining the success of a species. Finally, the direct effect of food concentration on the mortality will be investigated. Concentrations of food were chosen to cover the range found in natural environments (Sommer et al., 1986).

In short, we address the following question: to what degree do variations in the food concentrations affect the population growth of D.galeata, D.cucullata and their hybrid in a different manner?

\section{Method}

Animals

Daphnia galeata, D.cucullat a and the hybrid between these species were collected using a $120 \mu \mathrm{m}$ tow net from Tjeukemeer, a shallow eutrophic lake in the northern part of the Netherlands (Beattie et al., 1979). In the laboratory, the animals were placed individually into $100 \mathrm{ml}$ test tubes, and fed with a $1: 1$ mixture of Chlamydomonas globosa and Scenedesmus obliquus, with an algal carbon content of $1 \mathrm{mg} \mathrm{Cl}^{-1}$. The temperature was $17.5^{\circ} \mathrm{C}$, and the light-dark conditions were $16 \mathrm{~h}$ of light and $8 \mathrm{~h}$ of darkness. As soon as the animals produced newborns, the mothers were removed and the species were determined using allozym analysis (Wolf, 1982). Subsequently, the newborns were reared to maturity in the same medium as their mothers. The newborns produced by these animals were used for the experiments described below.

\section{Experimental design}

Different amounts of C.globosa were added to $0.45 \mu \mathrm{m}$ filtered Tjeukemeer water in order to obtain five (hybrid) or six (D.galeata and D.cucullata) different food levels. These were $0,1500,5000,10000,(20000)$ and 100000 cells $\mathrm{ml}^{-1}$, corresponding to an algal carbon content of $0,0.04,0.13,0.25,(0.50)$ and $2.5 \mathrm{mg} \mathrm{C}^{-1}$, respectively. The algae were cultured axenically in a 21 flowthrough system on a medium described elsewhere (Boersma and Vijverberg, 1994a). Every day the algae were harvested from the overflow bottle of the continuous culture. The culture medium of the algae was removed, to prevent the possible toxic effect of concentrated inorganic media, by centrifuging twice for $20 \mathrm{~min}$ at 3000 r.p.m., and by subsequent washing with distilled water. After this, the algae were resuspended in $0.45 \mu \mathrm{m}$ filtered Tjeukemeer water. The algal density was measured using a haemocytometer, by counting a minimum of 500 cells. Individual cells of $C$.globosa contained $4.75 \times 10^{-11} \mathrm{~g} \mathrm{C}$, which was equal to $53 \%$ of their dry weight.

The experiments were carried out at the same temperature and photoperiod as in the acclimatization phase. For each series, 40 neonates were collected within $12 \mathrm{~h}$ of birth and placed individually into $100 \mathrm{ml}$ test tubes. To avoid possible increased mortality as a result of handling, we measured two of the neonates from each brood. These neonates were then discarded and the rest of 
the batch was used for the experiments. The animals were selected so that the clonal composition of all series within a species was equal. All individuals were transferred to clean tubes with fresh medium daily. At the same time as this the animals were examined for moulting, by inspecting the medium for exuviae. The time needed to reach maturity and the number of juvenile instars were established. We used the time at which the first eggs were observed in the brood pouch as the time of maturity, although the development of the reproductive organs starts much earlier (Zaffagnini, 1987). Once the animals reached maturity, the number of eggs was counted and the length of the individuals was recorded for every adult instar. The animals were measured from the upper edge of the eye to the base of the tail spine. The numbers of newborns were recorded, the neonates were measured and then removed from the tubes. Growth and reproduction were measured until the animals reached the fourth adult instar, i.e. on average for $\sim 20$ days. The animals were then discarded because under natural conditions, judging by their sizes, animals rarely develop further than the fourth adult instar. The volume of the test tube in relation to the grazing pressure of the daphnids was large enough to guarantee only a small change in food concentration in $24 \mathrm{~h}$. After 1 day of feeding, algal concentration never differed by $>20 \%$ from the starting concentration.

We estimated the intrinsic rate of increase, $r$, using the Euler equation:

$$
1=\sum_{x=0}^{N} \mathrm{e}^{-r \cdot x} \cdot l_{x} \cdot m_{x}
$$

where $r$ is the per capita rate of increase for the population $\left(\right.$ day $\left.^{-1}\right), x$ is the age $(0,1 \ldots N), l_{x}$ is the probability of surviving to age $x$ and $m_{x}$ is the number of offspring born at age $x$. By default, $r$ cannot be computed from this equation when either $l_{x}$ or $m_{x}$ equals zero for all age classes. In such cases, $r$ was estimated directly from the death rate, since $r=-d$. Since both $r$ and $d$ are population measurements, it is not possible to directly compute standard errors (SEs), hence they were computed using a jackknifing method (Meyer et al., 1986).

To assess reproductive effort, defined here as the proportion of the total carbon which is invested in reproduction by each of the adult instars, a number of individuals were taken at random. Half of these individuals were dissected to release the eggs from the brood pouch. If possible, three eggs were used to determine the carbon content of the individual eggs. The other half of the animals was analysed for carbon intact (Boersma and Vijverberg, 1994c). Combining the length-carbon relationships of intact animals and the carbon content of individual eggs yields an estimate of reproductive effort.

All animals which were analysed carried eggs which were in the developmental stage in which the egg membranes have not yet been cast off. Since this developmental stage comprises $-30 \%$ of the total egg development time (Threlkeld, 1979), some bias may have been introduced as the carbon contents of the females increase during this period, as a result of growth and build-up of new eggs in the ovaries. However, it is not possible to dissect younger eggs from the brood pouch, analysing eggs in this stage yields the best possible assessment of parental investment in reproduction. 


\section{Results}

Growth

Higher food concentrations resulted in an increased size of the various instars (Figure 1). Daphnia galeata is the largest of the species and D.cucullata is the smallest. The hybrid is of intermediate size (Figure $1 \mathrm{a}, \mathrm{b}$ and $\mathrm{c}$ ). The number of juvenile instars was not constant over the different food levels. There was a decrease in number of juvenile instars with an increase in food concentration (Figure 2). No animal ever reached maturity at the food level without algae. At the lowest algal concentration $\left(0.04 \mathrm{mg} \mathrm{Cl}^{-1}\right)$, both $D$.cucullata and D.galeata $\times$ cucullata also did not produce any eggs within the experimental period. Consequently, the number of juvenile instars is undefined. The difference in the number of juvenile instars is reflected in the total duration of the juvenile period (Figure 3). Food concentration had a significant effect on the length of the juvenile period in all three species (D.galeata: $F_{4.172}=87.8 ; P<0.001$; D. galeata $\times$ cucullata: $F_{2.113}=162 ; P<0.001 ;$ D.cucullata: $F_{3.125}=3.93$; $P<0.005$ ). A significant species effect and an interaction between species and food level was also observed. The difference in total juvenile duration between the highest and the lowest food level was highest in D.galeata $\times$ cucullata, with a juvenile period of $13.3(\mathrm{SD}=3.2$ ) days at the lowest food level it reproduced $\left(0.13 \mathrm{mg} \mathrm{Cl}^{-1}\right)$ and of only $5.3(0.7)$ days at the highest food level. The difference was a factor of 2.5. In D.galeata, the variability of the total juvenile period was smaller, lasting $11.4(2.3)$ days at a food level of $0.04 \mathrm{mg} \mathrm{Cl}^{-1}$ and 6.4 (1.4) days at the highest food level. The variation of the juvenile periods in relation to food for D.cucullata was even smaller. Individuals of this species had a juvenile period of 10.1 (3.5) days at $0.13 \mathrm{mg} \mathrm{Cl}^{-1}$ and of $7.8(3.3)$ days at $2.5 \mathrm{mg} \mathrm{Cl}^{-1}$.

The differences in the juvenile period could not only be ascribed to a difference in the number of juvenile instars, but also to changes in the duration of the instars (Table I); the higher the food concentration, the shorter the duration of the instars. The variation in instar duration between the food levels in D.cucullata was relatively low compared with the other two species, only in one case (duration of the second juvenile instar) was a significant effect of food level found. Both D.galeata and D.galeata $\times$ - cucullata showed more of a response to differences in food concentration. Again, the hybrid was most variable in instar duration, with a longer duration of the instars than D.galeata at the lower food levels, and a shorter duration at the highest level. This is expressed as a significant species-food interaction for most instars. The juvenile instar period was shorter than the intermoult periods of adult instars. In addition, when an animal postponed maturation, the duration of this extra juvenile instar was shorter than the instar duration of the animals which matured, although the animals were of the same physiological age. This difference, tested with a $t$-test, was significant at the $P=0.05$ level in all but one case (compare J5 and Adl in D.galeata, and $\mathrm{J} 4$ and $\mathrm{Ad} 1$ in D.cucullata and the hybrid; Table I). Thus, when an animal postponed maturation it remained in the juvenile phase. This extra juvenile instar was not merely an adult instar without eggs, since once animals had matured $t$-tests revealed that no significant 
Resource depression in D.galeata, D.cucullata and hybrid
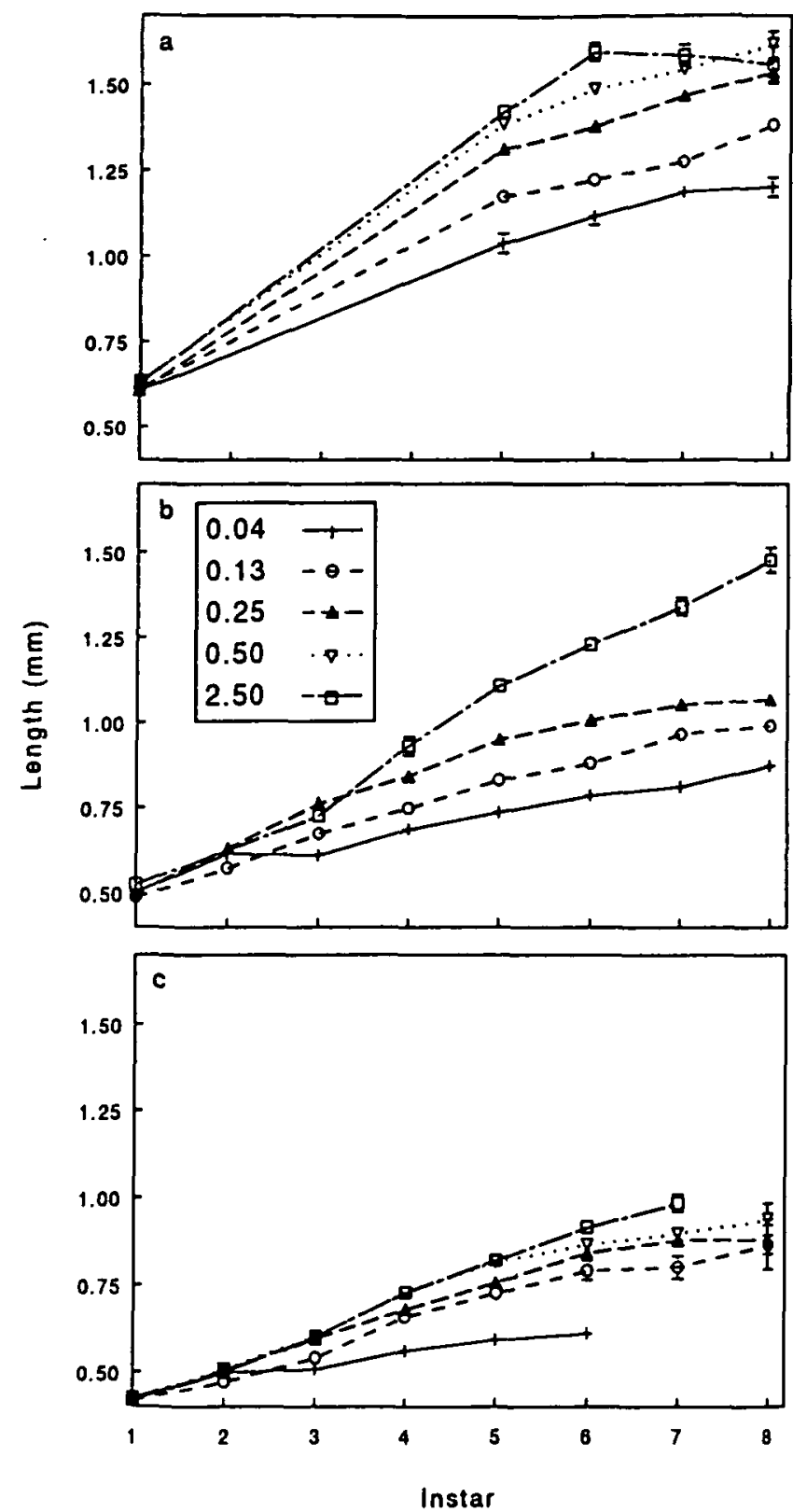

Fig. 1. Growth [mean length (mm) of successive instars \pm SE] of D.galeata (a), D.galeata $\times$ cucullata (b) and D.cucullata (c) at different food concentrations. In most cases the SE is smaller than the radius of the points. 
M.Boersma and J.Vijverberg

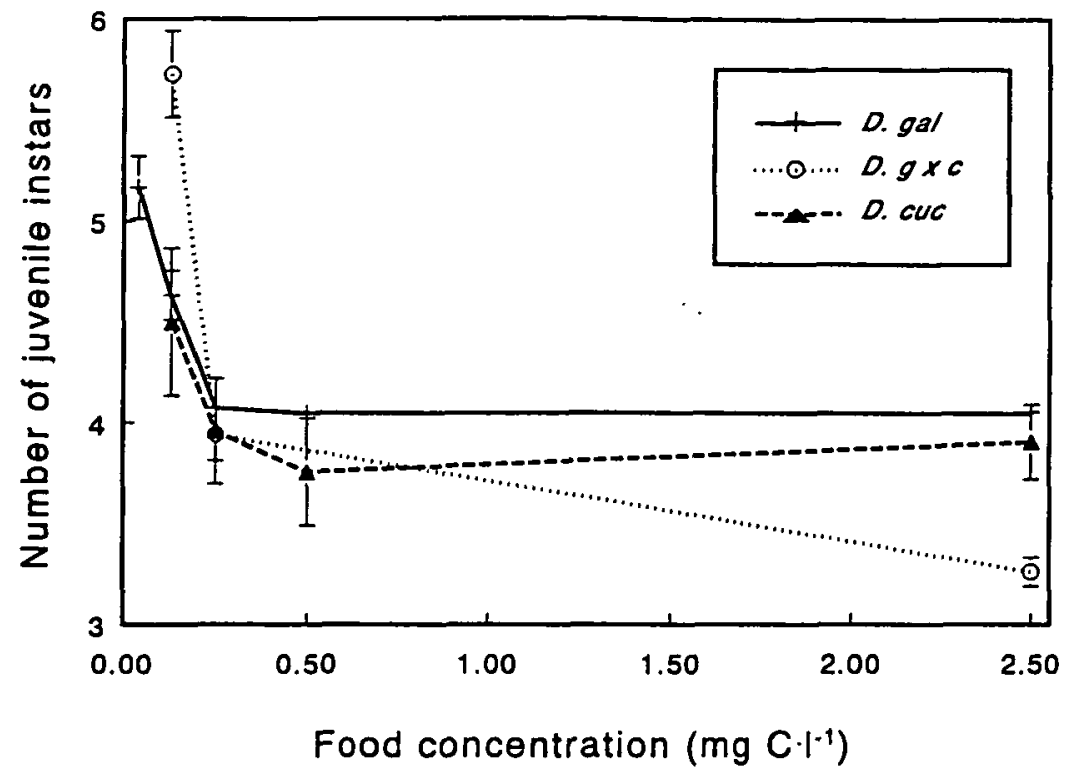

Fig. 2. Number of juvenile instars (mean $\pm S E$ ) of $D$.galeata ( $D$.gal: solid line, plus signs), D.galeata $\times$ cucullata (D.g $x \mathrm{c}$ : dotted line, circles) and D.cucullata (D.cuc: dashed line, triangles) at different food concentrations.

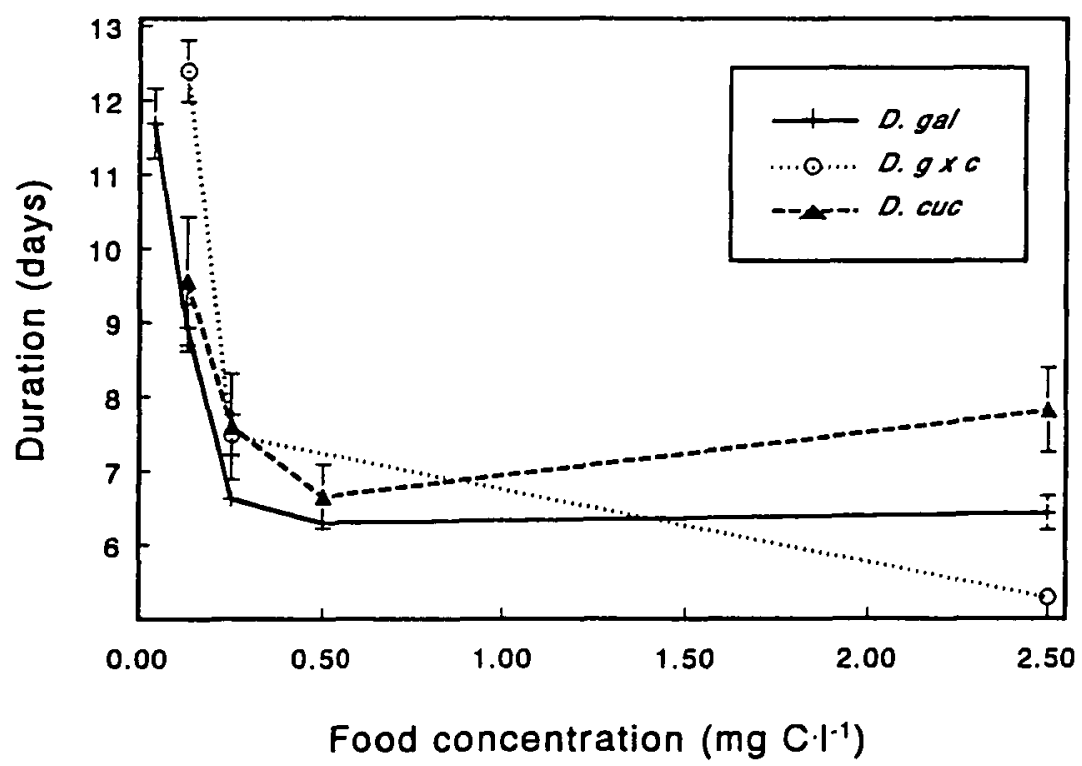

Fig. 3. Duration of the juvenile period (mean $\pm \mathrm{SE}$ ) of $D$.galeata (solid line, plus signs). D.galeata $x$ cucullata (dotted line, circles) and D.cucullata (dashed line, triangles) at different food concentrations.

1746 
Table I. Mean instar duration of D.galeata (a), D.galeata $\times$ cucullata (b) and D.cucullata (c) at different food concentrations (SD). $\mathrm{J} \mathrm{I}=$ first juvenile instar; $\mathrm{Adl}=$ first adult instar

\begin{tabular}{|c|c|c|c|c|c|c|c|c|}
\hline Food & JI & $J 2$ & $\mathrm{J3}$ & J4 & J5 & Adl & Ad2 & Ad3 \\
\hline \multicolumn{9}{|c|}{ (a D.galeata) } \\
\hline 0 & $\begin{array}{c}1.64 \\
(0.31)\end{array}$ & $\begin{array}{c}2.23 \\
(0.60)\end{array}$ & $\begin{array}{c}3.25 \\
(1.32)\end{array}$ & $\begin{array}{c}3.43 \\
(0.59)\end{array}$ & & & . & \\
\hline 0.04 & $\begin{array}{c}1.75 \\
(0.63)\end{array}$ & $\begin{array}{c}1.61 \\
(0.50)\end{array}$ & $\begin{array}{c}2.24 \\
(0.54)\end{array}$ & $\begin{array}{c}2.53 \\
(0.56)\end{array}$ & $\begin{array}{c}3.14 \\
(0.95)\end{array}$ & $\begin{array}{c}3.50 \\
(0.52)\end{array}$ & $\begin{array}{c}3.83 \\
(0.75)\end{array}$ & \\
\hline 0.13 & $\begin{array}{c}1.50 \\
(0.34)\end{array}$ & $\begin{array}{c}1.30 \\
(0.46)\end{array}$ & $\begin{array}{c}1.98 \\
(0.48)\end{array}$ & $\begin{array}{c}2.38 \\
(0.49)\end{array}$ & $\begin{array}{c}2.71 \\
(0.64)\end{array}$ & $\begin{array}{c}3.28 \\
(0.46)\end{array}$ & $\begin{array}{c}3.63 \\
(0.50)\end{array}$ & $\begin{array}{c}3.17 \\
(0.41)\end{array}$ \\
\hline 0.25 & $\begin{array}{c}1.35 \\
(0.55)\end{array}$ & $\begin{array}{c}1.53 \\
(0.51)\end{array}$ & $\begin{array}{c}1.55 \\
(0.56)\end{array}$ & $\begin{array}{c}2.13 \\
(0.34)\end{array}$ & $\begin{array}{c}2.33 \\
(0.58)\end{array}$ & $\begin{array}{c}3.21 \\
(0.62)\end{array}$ & $\begin{array}{c}3.37 \\
(0.50)\end{array}$ & $\begin{array}{c}3.70 \\
(0.48)\end{array}$ \\
\hline 0.50 & $\begin{array}{c}1.23 \\
(0.28)\end{array}$ & $\begin{array}{c}1.53 \\
(0.51)\end{array}$ & $\begin{array}{c}1.58 \\
(0.50)\end{array}$ & $\begin{array}{c}1.93 \\
(0.42)\end{array}$ & $\begin{array}{c}1.00 \\
(0.00)\end{array}$ & $\begin{array}{c}3.33 \\
(0.48)\end{array}$ & $\begin{array}{c}3.35 \\
(0.49)\end{array}$ & $\begin{array}{c}3.40 \\
(0.52)\end{array}$ \\
\hline 2.50 & $\begin{array}{c}1.42 \\
(0.36)\end{array}$ & $\begin{array}{c}1.47 \\
(0.56)\end{array}$ & $\begin{array}{c}1.50 \\
(0.56)\end{array}$ & $\begin{array}{c}1.92 \\
(0.84)\end{array}$ & $\begin{array}{c}2.50 \\
(0.71)\end{array}$ & $\begin{array}{c}2.86 \\
(0.35)\end{array}$ & $\begin{array}{c}3.58 \\
(0.52)\end{array}$ & $\begin{array}{c}3.50 \\
(0.54)\end{array}$ \\
\hline$F$ & 7.64 & 13.60 & 31.60 & 28.80 & 4.23 & 4.40 & 1.63 & 1.55 \\
\hline $\begin{array}{l}\text { d.f. } \\
P\end{array}$ & $\begin{array}{c}5,226 \\
(<0.001)\end{array}$ & $\begin{array}{l}5,223 \\
(<0.001)\end{array}$ & $\begin{array}{l}5,220 \\
(<0.001)\end{array}$ & $\begin{array}{l}5,211 \\
(<0.001)\end{array}$ & $\begin{array}{c}4,61 \\
(0.002)\end{array}$ & $\begin{array}{c}4,115 \\
(0.002)\end{array}$ & $\begin{array}{l}4.68 \\
\text { NS }\end{array}$ & $\begin{array}{l}3,30 \\
\text { NS }\end{array}$ \\
\hline \multicolumn{9}{|c|}{ (b D.galeata $\times$ cucullata) } \\
\hline 0 & $\begin{array}{l}2.10 \\
(1.44)\end{array}$ & $\begin{array}{c}4.00 \\
(0.00)\end{array}$ & & & & & & \\
\hline 0.04 & $\begin{array}{c}1.81 \\
(0.44)\end{array}$ & $\begin{array}{c}2.73 \\
(0.59)\end{array}$ & $\begin{array}{c}3.74 \\
(1.79)\end{array}$ & $\begin{array}{c}3.41 \\
(1.14)\end{array}$ & $\begin{array}{c}3.58 \\
(0.61)\end{array}$ & & & \\
\hline 0.13 & $\begin{array}{l}1.95 \\
(0.63)\end{array}$ & $\begin{array}{c}1.83 \\
(0.78)\end{array}$ & $\begin{array}{c}2.28 \\
(0.51)\end{array}$ & $\begin{array}{c}2.77 \\
(0.65)\end{array}$ & $\begin{array}{c}2.52 \\
(0.51)\end{array}$ & $\begin{array}{c}3.38 \\
(0.58)\end{array}$ & $\begin{array}{c}3.56 \\
(0.51)\end{array}$ & $\begin{array}{c}3.61 \\
(0.84)\end{array}$ \\
\hline 0.25 & $\begin{array}{c}1.63 \\
(0.68)\end{array}$ & $\begin{array}{c}1.84 \\
(0.44)\end{array}$ & $\begin{array}{c}2.00 \\
(0.68)\end{array}$ & $\begin{array}{c}2.03 \\
(0.20)\end{array}$ & $\begin{array}{c}2.00 \\
(0.71)\end{array}$ & $\begin{array}{c}3.11 \\
(0.32)\end{array}$ & $\begin{array}{c}3.41 \\
(0.50)\end{array}$ & $\begin{array}{c}3.25 \\
(0.72)\end{array}$ \\
\hline \multicolumn{9}{|l|}{0.50} \\
\hline 2.50 & $\begin{array}{c}1.38 \\
(0.42)\end{array}$ & $\begin{array}{c}1.48 \\
(0.51)\end{array}$ & $\begin{array}{c}1.93 \\
(0.50)\end{array}$ & $\begin{array}{c}1.80 \\
(0.42)\end{array}$ & & $\begin{array}{c}2.75 \\
(0.44)\end{array}$ & $\begin{array}{c}2.98 \\
(0.17)\end{array}$ & $\begin{array}{c}3.06 \\
(0.24)\end{array}$ \\
\hline$F$ & 6.13 & 32.3 & 26.7 & 20.2 & 26.60 & 15.20 & 17.30 & 5.52 \\
\hline $\begin{array}{l}\text { d.f. } \\
P\end{array}$ & $\begin{array}{c}4,179 \\
(<0.001)\end{array}$ & $\begin{array}{c}4,163 \\
(<0.001)\end{array}$ & $\begin{array}{l}3,143 \\
(<0.001)\end{array}$ & $\begin{array}{l}3,89 \\
(<0.001)\end{array}$ & $\begin{array}{l}2,50 \\
(<0.001)\end{array}$ & $\begin{array}{l}2,92 \\
(<0.001)\end{array}$ & $\begin{array}{l}2,87 \\
(<0.001)\end{array}$ & $\begin{array}{c}2,87 \\
(0.01)\end{array}$ \\
\hline \multicolumn{9}{|c|}{ (c D.cucullata) } \\
\hline 0 & $\begin{array}{c}1.94 \\
(0.79)\end{array}$ & & & & & & & \\
\hline 0.04 & $\begin{array}{c}1.87 \\
(0.83)\end{array}$ & $\begin{array}{c}2.63 \\
(0.77)\end{array}$ & $\begin{array}{c}2.57 \\
(0.54)\end{array}$ & $\begin{array}{c}2.66 \\
(0.58)\end{array}$ & & & & \\
\hline 0.13 & $\begin{array}{c}1.94 \\
(0.71)\end{array}$ & $\begin{array}{c}2.20 \\
(0.80)\end{array}$ & $\begin{array}{c}2.22 \\
(0.79)\end{array}$ & $\begin{array}{c}2.23 \\
(0.65)\end{array}$ & & $\begin{array}{c}3.17 \\
(0.41)\end{array}$ & $\begin{array}{l}3.00 \\
(-)\end{array}$ & $\begin{array}{l}3.00 \\
(-)\end{array}$ \\
\hline 0.25 & $\begin{array}{c}1.71 \\
(0.58)\end{array}$ & $\begin{array}{c}2.00 \\
(0.68)\end{array}$ & $\begin{array}{c}2.02 \\
(0.61)\end{array}$ & $\begin{array}{c}2.18 \\
(0.50)\end{array}$ & & $\begin{array}{c}3.25 \\
(0.45)\end{array}$ & $\begin{array}{c}2.90 \\
(0.32)\end{array}$ & $\begin{array}{c}3.60 \\
(0.55)\end{array}$ \\
\hline 0.50 & $\begin{array}{c}1.77 \\
(0.64)\end{array}$ & $\begin{array}{c}1.87 \\
(0.69)\end{array}$ & $\begin{array}{c}2.00 \\
(0.42)\end{array}$ & $\begin{array}{c}2.17 \\
(0.39)\end{array}$ & & $\begin{array}{c}3.09 \\
(0.29)\end{array}$ & $\begin{array}{c}3.21 \\
(0.58)\end{array}$ & $\begin{array}{c}3.00 \\
(0.58)\end{array}$ \\
\hline 2.50 & $\begin{array}{c}1.86 \\
(0.57)\end{array}$ & $\begin{array}{c}1.78 \\
(0.58)\end{array}$ & $\begin{array}{c}2.14 \\
(0.59)\end{array}$ & $\begin{array}{c}2.18 \\
(0.40)\end{array}$ & & $\begin{array}{c}3.08 \\
(0.27)\end{array}$ & $\begin{array}{c}3.13 \\
(0.34)\end{array}$ & $\begin{array}{c}3.11 \\
(0.60)\end{array}$ \\
\hline$F$ & 0.84 & 6.99 & 1.73 & 0.65 & & 1.05 & 1.06 & 1.17 \\
\hline d.f. & 5,279 & 4,195 & 4,150 & 4,80 & & 3,67 & 3,37 & 3,18 \\
\hline$P$ & NS & $(<0.001)$ & NS & NS & & NS & NS & NS \\
\hline
\end{tabular}


differences existed between the instar durations of animals with and without eggs.

From the data on the growth of the three species at the different food levels, we can estimate the food concentration at which growth is maximal. Since exact estimation of this food level is difficult, we decided to estimate the food concentration at which the size of the animals is half the maximum attainable size $\left(K_{\mathrm{m}}\right)$. This was achieved by fitting a modified Monod saturation curve through the data. Although the concept of incipient limiting concentration (ILC) mostly refers to a type I response (Mullin et al., 1975), different individuals are likely to show slightly different responses to the different food concentrations, and Mullin et al. (1975) found no significant differences in the explained variance between a type I and a type II response curve fit. Hence, this approach seems justified. The main advantage of fitting a type II response is that all data points are used to fit one curve, whereas in the type I case two different curves are fitted. Since animals are born with a certain size, the curves do not go through the origin in the food concentration-size graph. This analysis was carried out for the first possible adult instar of the three species (fifth instar for D.galeata, and fourth instar for the hybrid and D.cucullata) (Figure 4). Daphnia cucullata was highly responsive to a slight increase in food concentration at low levels, but its reaction was relatively constant at higher levels, i.e. $K_{\mathrm{m}}=0.057(\mathrm{SE}=0.046)$ $\mathrm{mg} \mathrm{C} \mathrm{^{-1 }}$, which is not significantly different from zero at $P=0.05$. The $K_{\mathrm{m}}$ value for D.galeata was higher, i.e. $K_{\mathrm{m}}=0.107(0.016) \mathrm{mg} \mathrm{Cl}^{-1}$, and the hybrid showed the highest $K_{\mathrm{m}}$ value of $0.157(0.069) \mathrm{mg} \mathrm{Cl}^{-1}$.

\section{Reproduction}

Size at maturity. Size at maturity differed between the species and the food concentrations (Figure 5). Although the variation in size at maturity was small in both the hybrid and $D$.cucullata, all food concentration effects were significant in all of the species (D.galeata: $F_{4.167}=49.8 ; P<0.001 ; D$.galeata $\times$ cucullata: $F_{2.94}=6.55 ; P=0.002 ;$ D.cucullata: $\left.F_{3.95}=3.27 ; P=0.024\right)$.

When the variance in length of the size at maturity is compared with the variance in length of the first possible adult instar for the three species, we see that the variance in size at maturity was significantly smaller in all three cases, with $F$ values of 1.61 (d.f. 191, 176; $P<0.001$ ) for D.galeata, 1.721 (d.f. 107, 106; $P=0.003$ ) for the hybrid and 2.49 (d.f. 146, 102; $P<0.001$ ) for D.cucullata.

Egg number. The number of eggs produced by the first adult instars increased with increasing food levels, with the exception of the two higher food levels for D.galeata (Figure 6). At the highest food level, the production of eggs in D.galeata decreased sharply in the third adult instar, and was less than the number of eggs produced at the lower levels. At the higher food levels the number of eggs generally increased with size of the mother, whereas at the lower levels the number of eggs produced was relatively constant. This suggests that at the higher food levels the space in the brood pouch or the egg-producing 


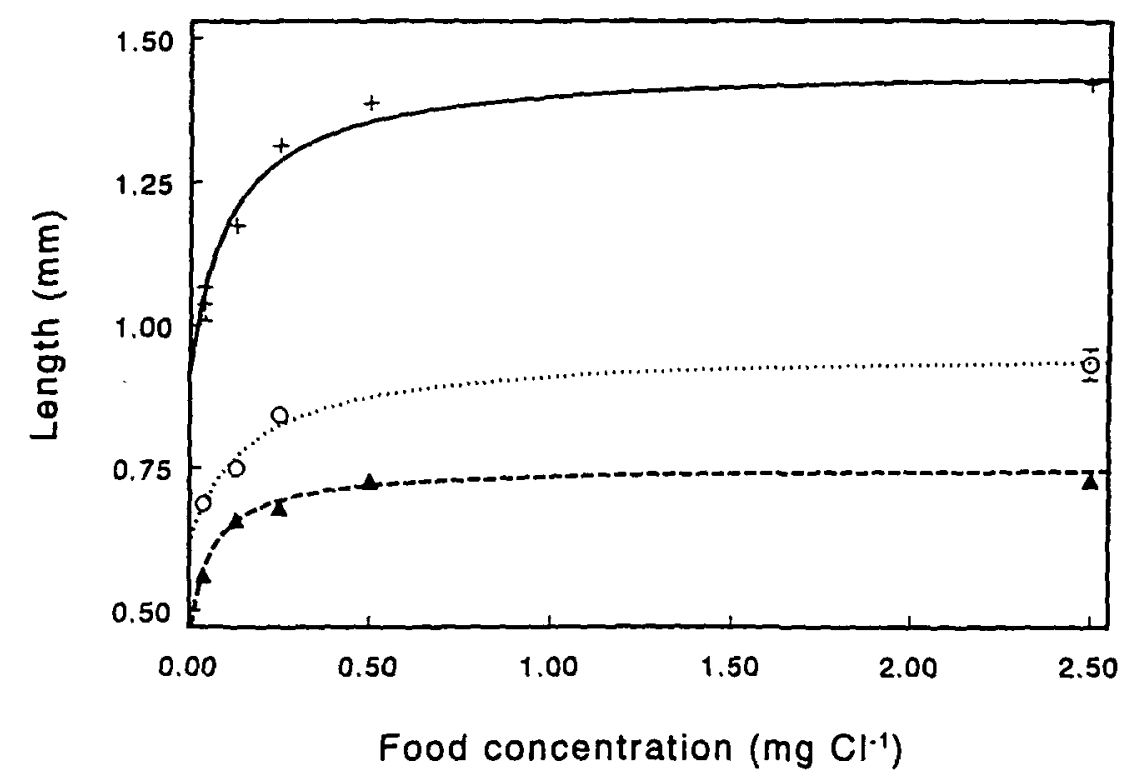

Fig. 4. Sizes of the first possible adult instar of D.galeata (solid line, plus signs). D.galeata $\times$ cucullata (dotted line, circles) and D. cucullata (dashed line, triangles) in relation to the food concentration. In most cases the $S E$ is smaller than the radius of the points. A Monod saturation curve is fitted through the data.

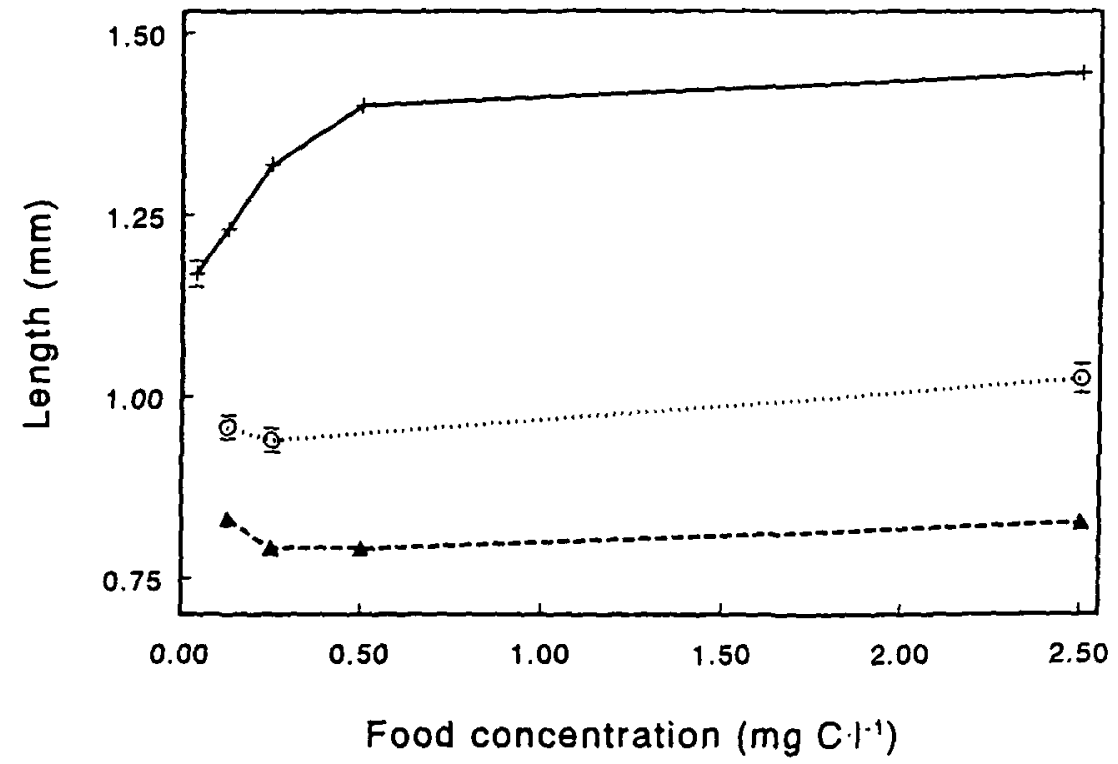

Fig. 5. Size of the first aduit instar (mean $\pm \mathrm{SE}$ ) of D.galeata (solid line, plus signs). D.galeata $\times$ cucullata (dotted line, circles) and D.cucullata (dashed line. triangles) at different food concentrations. In some cases the SEs are smaller than the radius of the points 

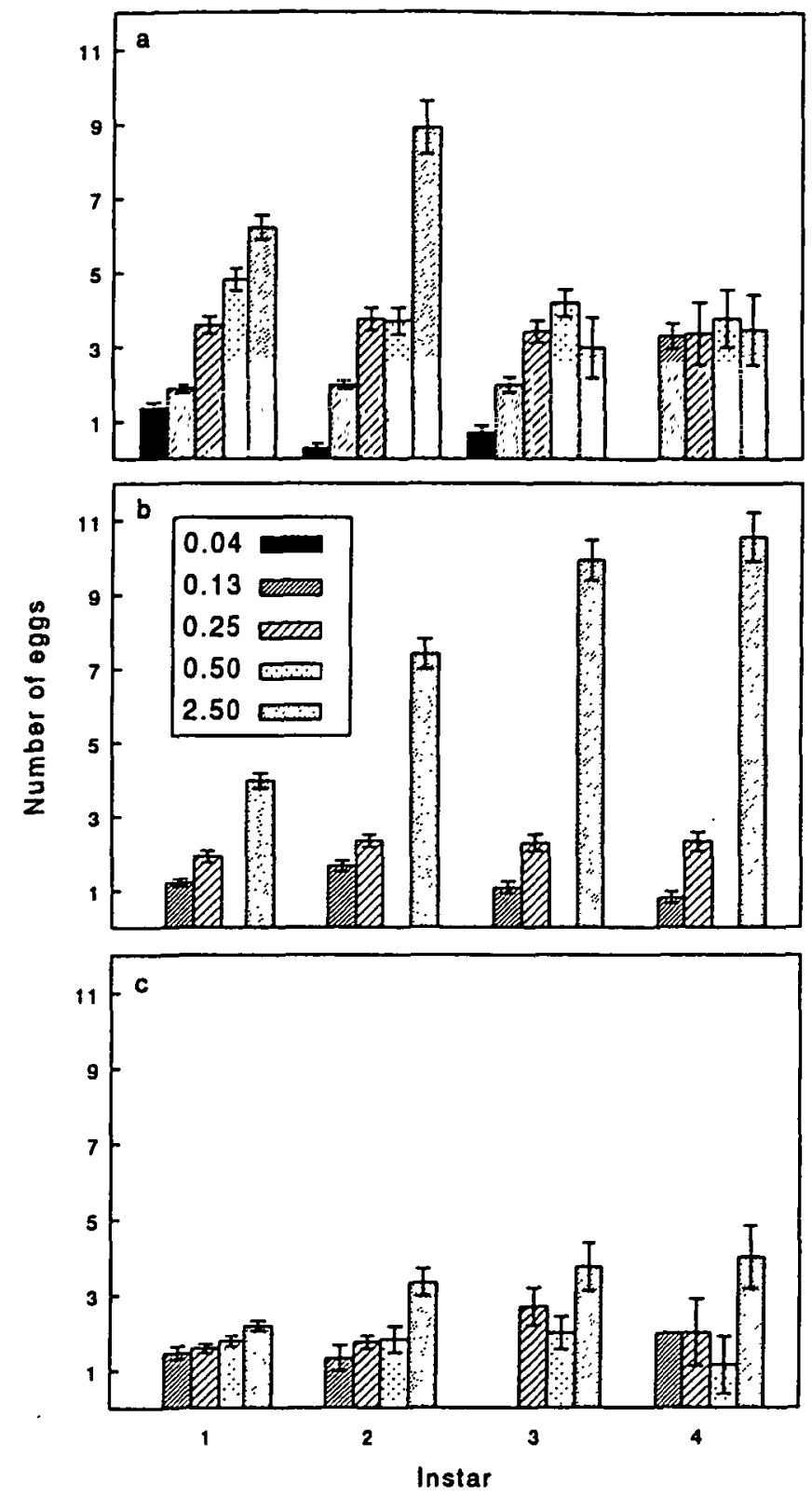

Fig. 6. Mean number of eggs (mean $\pm \mathrm{SE}$ ) fo D.galeata (a), D.galeata $\times$ cucullata (b) and D.cucullata (c) of different adult instars at different food concentrations. 
capacity of the ovarium is limiting, whereas at the lower food levels the amount of energy which can be allocated to reproduction is limiting the brood size.

\section{Mortality}

Mortality was defined as the percentage of animals which died per day. The effect of species and food concentration was analysed using a two-way ANOVA. Since per series only one measurement of mortality was available, the 'withinseries' variation could not be calculated. To test the effect of species and food concentration, the mean squares of these factors were tested over the interaction term, under the assumption that this interaction term was not significant. Mortality was highest at the lowest food concentration, with no algae added (Table II), which resulted in a significant concentration effect $\left(F_{4.8}=4.60 ; P=\right.$ $0.03)$, and masked the different reactions of the species $\left(F_{2.8}=2.60 ; P=\right.$ $0.13)$. When this complete starvation level was deleted from the analysis, the concentration effect disappeared $\left(F_{3.6}=1.47 ; P=0.31\right)$, although there was a trend of decreasing mortality with increasing food concentrations. Species differed significantly $\left(F_{2.6}=11.39 ; P=0.009\right)$, with $D$.galeata showing the lowest mortality and D.cucullata showing the highest mortality.

Since the animals were discarded at their fourth adult instar, the mortality observed was not caused by senescence, but by the ambient culture conditions, including handling, although the obvious handling casualties were omitted from the mortality computation. The handling mortality was probably not very important, even though D.cucullata individuals seemed to be more susceptible to handling problems than individuals of the other two species.

\section{Growth, reproduction and mortality}

Reproductive effort, defined as the proportion of the total amount of carbon which is allocated to reproduction, was dependent on the food concentration. In general, an increase in reproductive effort with food concentration could be observed (Figure 7). The maximum effort for D.galeata and D.cucullata was

Table II. Mortality (percentage day ${ }^{-1}$ ) of D.galeata, D.galeata $\times$ cucullata and D.cucullata at different food concentrations ( $\mathrm{mg} \mathrm{C \textrm {I } ^ { - 1 }}$ ). Jackknife $\mathrm{SEs}$ are given in parentheses

\begin{tabular}{lccc}
\hline Food & D.galeata & D.galeata $\times$ cucullata & D.cucullata \\
\hline 0 & 2.44 & 21.07 & 18.32 \\
& $(0.007)$ & $(0.025)$ & $(0.022)$ \\
0.04 & 0.52 & 3.21 & 6.00 \\
& $(0.003)$ & $(0.006)$ & $(0.012)$ \\
0.13 & 0.55 & 1.25 & 5.00 \\
& $(0.003)$ & $(0.004)$ & $(0.009)$ \\
0.25 & 0.43 & 0.97 & 2.88 \\
& $(0.003)$ & $(0.004)$ & $(0.008)$ \\
0.50 & 0.00 & & 4.23 \\
& $(0.000)$ & 0.00 & $(0.009)$ \\
2.50 & 2.03 & $(0.000)$ & 3.67 \\
& $(0.007)$ & $0.008)$ \\
\hline
\end{tabular}


found at $0.5 \mathrm{mg} \mathrm{Cl}^{-1}$. Both parent species showed a relatively high reproductive effort level as compared with the hybrid at the lower food levels, whereas no significant difference existed at the highest food concentration. For each species the reproductive effort was independent of age.

Since both growth and reproduction increased with an increase in food, the rate of population increase $(r)$ increased with food concentration for all three species (Table III). Daphnia cucullata showed the lowest value for $r$ in almost all circumstances. Daphnia galeata had a relatively high $r$ at low food concentrations, whereas the hybrid had a significantly higher value for $r$ than both parental species at the highest food level.

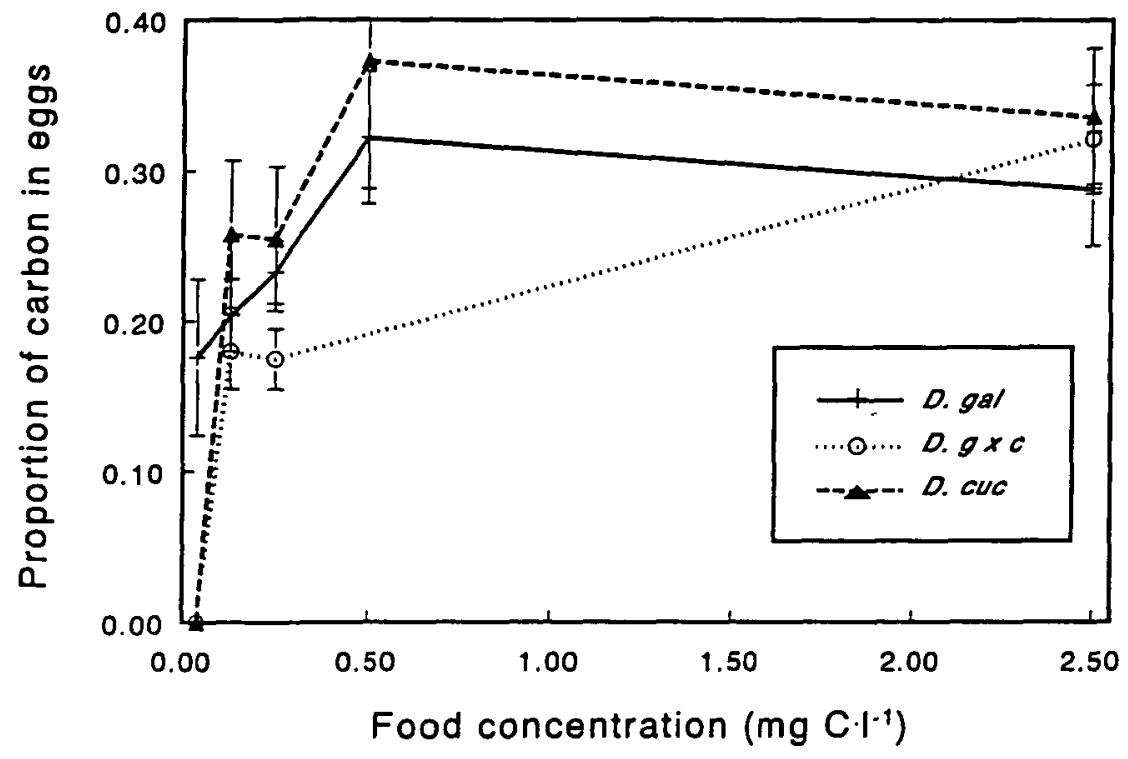

Fig. 7. Proportion of the total carbon content of an animal, which is invested in reproduction (mean \pm SD), for D.galeata (solid line, plus signs), D.galeata $\times$ cucullata (dotted line, circles) and D.cucullata (dashed line, triangles) at different food concentrations.

Table III. Values of the rate of population increase $(r)$ of D.galeata, D.galeata $\times$ cucullata and D.cucullata at different food concentrations. SEs of the jackknife method are given in parentheses

\begin{tabular}{lccc}
\hline Food & D.galeata & D.galeata $\times$ cucullata & D.cucullata \\
\hline 0 & -0.02 & -0.21 & -0.18 \\
& $(0.007)$ & $(0.025)$ & $(0.022)$ \\
0.04 & 0.03 & -0.03 & -0.06 \\
& $(0.010)$ & $(0.006)$ & $(0.030)$ \\
0.13 & 0.11 & 0.04 & -0.03 \\
& $(0.005)$ & $(0.007)$ & $(0.018)$ \\
0.25 & 0.19 & 0.13 & 0.06 \\
& $(0.007)$ & $(0.007)$ & $(0.014)$ \\
0.50 & 0.21 & & 0.07 \\
& $(0.006)$ & 0.29 & $(0.016)$ \\
2.50 & 0.24 & $(0.014)$ & 0.11 \\
& $(0.011)$ & $(0.012)$ \\
\hline
\end{tabular}




\section{Discussion}

With the above results, we showed that the three different taxa of the Daphnia longispina complex have different life history traits under different food conditions. The concentration of particulate organic carbon in Tjeukemeer ranges from 6 to $10 \mathrm{mg} \mathrm{Cl}^{-1}$ (Gulati, 1975). However, in the growing season $\sim 90 \%$ of the algal biomass consists of cyanobacteria, mainly Oscillatoria species (Moed and Hoogveld, 1982), and although daphnids are reported to feed on filamentous blue-green algae (Bloem and Vijverberg, 1984), cyanobacteria are usually regarded as poor-quality food (e.g. Ahlgren et al., 1990). Therefore, the concentration of favourable food in Tjeukemeer is likely to be lower than the ILC values for the Daphnia species, which means that populations of Daphnia would be food limited during at least parts of the year (Vijverberg, 1976). This is corroborated by our results of a seasonal study of Daphnia conditions, showing food limitations in large parts of the year (Boersma and Vijverberg, 1994c).

By culturing the daphnids under static conditions, the differences in response between the food levels may have been overestimated. As larger animals deplete their resources more than smaller ones, the differences between the species are also likely to have been exaggerated by the static culture conditions. However, as the differences in algal concentration before and after 1 day of feeding were relatively small, the extent of the different overestimations is likely to be small.

For all three species, the threshold for growth is $<0.04 \mathrm{mg} \mathrm{Cl}^{-1}$, since on this food level we still observed an increase in length. The threshold value for reproduction differed for the three species. Daphnia galeata had the lowest threshold value $\left(<0.04 \mathrm{mg} \mathrm{C}^{-1}\right)$. Both D.galeata $\times$ cucullata and D.cucullata started reproducing between 0.04 and $0.13 \mathrm{mg} \mathrm{Cl}^{-1}$, although the threshold value for D.cucullata is likely to have been higher since the percentage of animals actually maturing at $0.13 \mathrm{mg} \mathrm{C}{ }^{-1}$ was still small. Lampert (1977) reported threshold values for growth of between 0.04 and $0.12 \mathrm{mg} \mathrm{C}^{-1}$ for D.pulex, i.e. values somewhat higher than those found in this study. This could be a result of the use of a different algal food, which is known to have an effect on the threshold concentrations (Lampert, 1977). The fact that Duncan et al. (1985) were able to culture individuals of $D$.pulicaria and D.hyalina at food levels as low as $0.005 \mathrm{mg} \mathrm{C}^{-1}$ suggests that the threshold values in their experiments were lower than the values we found, although it is unclear from their paper whether there was both growth and reproduction in these circumstances. Gliwicz and Lampert (1990) also reported rather low threshold values for growth, and an increase in the threshold values with a decrease in animal size, i.e. D.pulicaria: $0.016 \mathrm{mg} \mathrm{Cl}^{-1}$; D.hyalina: $0.018 \mathrm{mg} \mathrm{Cl}^{-1} ;$ D.cucullata: $0.038 \mathrm{mg} \mathrm{Cl}^{-1}$. This same size dependence can be seen in our results.

The differences in $K_{\mathrm{m}}$ values were relatively small. The values ranged from $0.057 \mathrm{mg} \mathrm{C}^{-1}$ for D.cucullata to $0.157 \mathrm{mg} \mathrm{C}^{-1}$ for D.galeata $\times$ cucullata. These values are in close agreement with the value of $\pm 0.15 \mathrm{mg} \mathrm{Cl}^{-1}$ found by Bohrer and Lampert (1988) for Daphnia magna. These results may provide the impression that, since D.cucullata has a lower $K_{\mathrm{m}}$ value for growth than the larger D.galeata, the former species would be a better competitor under low 
food conditions (see also Lynch, 1977; Tillmann and Lampert, 1984; Tessier and Goulden, 1987). One should, however, bear in mind that $K_{\mathrm{m}}$ values, like ILC values, are a relative measurement of the species performance as related to its own maximum performance under optimal conditions. From our experiments, it is clear that although D.cucullata has a lower $K_{\mathrm{m}}$ value than both other species, its maximal growth and reproduction are lower and, thus, its competitive ability is poor over the whole range of food concentrations when compared with D.galeata and the hybrid.

It is clear that the growth rate was influenced by the food level for all three species. The size of the first adult instar was, however, more constant than the size of any specific instar. This was caused by a different number of juvenile instars at the different food levels. At lower food levels, animals postponed maturity and had one or more additional juvenile instar. That the onset of reproduction is determined by size rather than by age has also been reported by Taylor (1985) in D.pulex and D.pulicaria, and was further supported by Ebert (1992). However, Urabe (1991) found that all animals mature in the same instar in Bosmina longirostris, independent of the food level. Furthermore, our study indicated that there was a minimal number of juvenile instars in all three species. This was especially clear for $D$.galeata. Individuals reared at lower food levels matured at a length equivalent to the length of the fourth juvenile instar at higher levels. Apparently, although size seems to trigger maturation, a D.galeata individual needs at least four juvenile instars to mature.

Instar duration varied between the different food levels. Low food levels resulted in an increase in instar duration both in juvenile and adult instars (see also Urabe, 1988, 1991; Guisande and Gliwicz, 1992), and this was not only the case at very low food conditions (Romanovsky, 1984). In some studies, egg development time was distinguished from the time between two moults of the mothers (Vijverberg, 1976). However, Zaffagnini (1987), in an extensive study on reproduction in Daphnia, showed that the time of egg development corresponded to the time required for moulting of the adult female. Moreover, we did not find any evidence of an increase in the period between release of the newborns and the moulting of the female at the lower food levels, implying that egg development time also changed with food concentration. This could have an important implication in computations of birth and death rates in cladoceran zooplankton, since the computation of a birth rate usually only takes into account the change in egg development time with changing temperature (e.g. Paloheimo, 1974). This means that under low food conditions the birth rate will be overestimated, and the same will happen to the death rate. Since instar duration varies from $\sim 2.8$ to 3.5 days in D.galeata, this may cause a difference in the birth rate computed according to Paloheimo (1974) of $25 \%$. Thus, in computations of birth rates it is advisable to also take food conditions into consideration, since the instar duration times will be influenced.

Reproduction decreased dramatically in D.galeata at the highest food level in later instars. This we believe to have been an artefact, as in a parallel series of D.galeata fed with S.obliquus reproduction continued to increase in the older instars (Boersma and Vijverberg, 1994b). Moreover, several workers have 
described the relationship of egg number with age (e.g. Ingle et al., 1937; Weglenska, 1971; Vijverberg, 1976; Taylor, 1985; Lynch, 1989, 1992; Urabe, 1988; Semenchenko, 1990; Groeger et al., 1991) and none of the authors cited above reported the observed phenomenon of the sudden decrease in egg numbers. Reproduction may decrease with increasing age, but this usually only happens with very old individuals, and not with third or fourth instars as observed in this study (Ingle et al., 1937).

Reproductive effort clearly increased with an increase in food level. This was also found by Taylor (1985), who showed that the proportion of the weight which was invested in reproduction not only increased with food level, but also with female length, and by Glazier (1992) who reported values as high as $50 \%$ for reproductive effort. However, Guisande and Gliwicz (1992) did not find a difference in reproductive effort in response to different food concentrations.

We observed a difference in mortality between the three species, with D.cucullata showing the highest mortality. These differences should be extrapolated with care, since predation as a source of mortality was excluded from the laboratory experiments. Mortality rates under natural circumstances may vary between 10 and $60 \%$ day $^{-1}$ (Vijverberg and Richter, 1982). Only at the lowest food level was the mortality sufficiently high to affect seasonal dynamics of the species. At all higher food concentrations, mortality caused by the food conditions is insignificant when compared to the total mortality in the field. The mortality of D.galeata at the lowest food level is relatively small compared with the others, which suggests that $D$.galeata may be less susceptible to low food conditions when compared with the other two species.

Owing to the negative exponent in the computation of $r$, the influence of older age classes in the computation of $r$ is small, and hence the influence of the possibly artefactual decrease in fecundity with age on $r$ will be small. We found that the hybrid showed the highest value for $r$ at the high food level $(r=0.29$ day $\left.^{-1}\right)$, a value higher than that $\left(0.21 \mathrm{day}^{-1}\right)$ found by Weider and Wolf (1991) at a somewhat lower food concentration. Daphnia cucullata showed the lowest $r$ values. Our maximum value of $0.11 \mathrm{day}^{-1}$ corresponds well with the value found by Ebert and Jacobs (1991) $\left(0.12 \mathrm{day}^{-1}\right)$ at similar food conditions. Other authors also reported lower rates of population increase for D.cucullata as compared with D.galeata and D.galeata $\times$ cucullata (Weider and Wolf, 1991; Spaak and Hoekstra, 1994). It could be argued that the $r$ values reported here for D.cucullata are too low, as delicate species such as D.cucullata are more difficult to handle, and hence will show mortality rates which are too high. However, if $r$ values are calculated under the assumption that $l_{x}=1$ (mortality is zero) for all species and food concentrations, the $r$ values for $D$.galeata and for $D$.galeata $\times$ cucullata hardly change. All $r$ values for D.cucullata increase slightly, but the overall patterns do not change. Hence, the differences in $r$ between the species and food levels were mainly caused by differences in fecundity. The $r$ values for D.cucullata under field conditions can be higher than the maximum values found in our cultures in certain periods of the year (M.Boersma, personal observation). This could be caused by higher temperatures in the field in certain periods of the year, but could also be a result of better 
feeding conditions in the lake, as compared to the mono-algal diets provided in our cultures (see also Boersma and Vijverberg, 1994c).

In the present study, the different Daphnia species reacted differently to changes in ambient food conditions. Daphnia cucullata was relatively constant with regard to all traits measured, so long as the food concentration was above a certain level. The hybrid was most variable in its behaviour towards differences in food concentration. This was in contrast to the findings of Yampolsky and Kalabushkin (1991), who found that the more heterozygous animals were less sensitive to changes in the environment. Daphnia galeata $\times$ cucullata did relatively poorly at low food concentrations, and grew well compared with the others at higher food levels. Our results suggest that given the food sources used in this study, in environments with low fish predation D.cucullata will always be outcompeted by the two other species, because of its low $r$ value. However, D.galeata and D.cucullata may show some form of niche segregation (Boersma, 1994), leading to a decrease in the competition between the two parental species, and hence the possibility of co-existence. Since $D$.galeata and the hybrid do seem to compete for resources under natural circumstances, the former will probably outcompete the hybrid at low food levels. The hybrid is expected to be the most abundant species at the higher food levels (see also Spaak and Hoekstra, 1994).

We showed (Boersma and Vijverberg, 1994c) that the populations of the three Daphnia species are food limited during the largest part of the year. This, combined with the results found by Brendelberger and Geller (1985) on the relatively small differences in mesh sizes of the filtering apparatus in the different Daphnia species under consideration, makes it likely that food competition between the Daphnia species plays a role in determining their relative densities during the season (Boersma, 1994). A decrease in food conditions will have the most severe effect on the hybrid, as a result of the large differences in $r$ between the highest and the lowest food concentrations. The large $r$ values of $D$.galeata $\times$ cucullata at high food concentrations may, however, explain the temporal success of this hybrid in eutrophic lakes.

\section{Acknowledgements}

These investigations were supported by the Life Science Foundation (SLW), which is subsidized by the Netherlands Organization for Scientific Research (NWO). We thank Aafje Landman, Theo Frank and Diana Tischer for their assistance in the laboratory, and Karen Wiltshire, Onno van Tongeren, Piet Spaak, Joop Ringelberg, Wolf Mooij and Ramesh Gulati for their comments on the manuscript.

\section{References}

Ahigren.G., Lundstedt.L., Brett,M.T. and Forsberg.C. (1990) Lipid composition and food quality of some freshwater phytoplankton for cladoceran zooplankters. J. Plankton Res., 12, 809-818.

Beattie.D.M., Golterman,H.L. and Vijverberg.J. (1979) An introduction to the limnology of the Friesian Lakes. Hydrobiologia, 58, 49-64. 
Bloem,J. and Vijverberg,J. (1984) Some observations on the diet and food selection of Daphnia hyalina (Cladocera) in an eutrophic lake. Hydrobiol. Bull., 18, 39-45.

Boersma,M., (1994) On the seasonal dynamics of Daphnia species in a shallow eutrophic lake. Thesis, University of Amsterdam, $160 \mathrm{pp}$.

Boersma,M. and Vijverberg,J. (1994a) Evidence of possible toxic effects on Daphnia resulting from the green alga Scenedesmus obliquus. Hydrobiologia, in press.

Boersma,M. and Vijverberg,J. (1994b) Synergistic effects of different food species on life history traits of Daphnia galeata. Hydrobiologia, in press.

Boersma,M. and Vijverberg.J. (1994c) Seasonal variations in the condition of two Daphnia species and their hybrid in a eutrophic lake: evidence for food limitation J. Plankton Res., 16, 1793-1809.

Boersma,M., van Densen,W.L.T. and Vijverberg,J. (1991) The effect of predation by smelt (Osmerus eperlanus) on Daphnia hyalina in a shallow eutrophic lake. Verh. Int. Ver. Limnol., 24, 2438-2445.

Bohrer,R.N. and Lampert,W. (1988) Simultaneous measurement of the effect of food concentration on assimilation and respiration in Daphnia magna Straus. Func. Ecol., 2, 463-471.

Brendelberger, $H$. and Geller,W. (1985) Variability of filter structures in eight Daphnia species: mesh sizes and filtering areas. J. Plankton Res., 7, 473-486.

Duncan,A., Lampert, W. and Rocha,O. (1985) Carbon weight on length regressions of Daphnia spp. grown at threshold food concentrations. Verh. Int. Ver. Limnol., 22, 3109-3115.

Ebert,D. (1992) A food-independent maturation threshold and size at maturity in Daphnia magna. Limnol. Oceanogr., 37, 878-881.

Ebert,D. and Jacobs.J. (1991) Differences in life-history and aging in 2 clonal groups of Daphnia cucullata Sars (Crustacea, Cladocera). Hydrobiologia, 225, 245-253.

Glazier,D.S. (1992) Effects of food, genotype, and maternal size and age on offspring investment in Daphnia magna. Ecology, 73, 910-926.

Gliwicz,Z.M. (1985) Predation or food limitation: an ultimate reason for extinction of planktonic cladoceran species. Arch. Hydrobiol. Beih. Ergebn. Limnol., 21, 419-430.

Gliwicz,Z.M. and Lampert,W. (1990) Food thresholds in Daphnia species in the absence and presence of blue-green filaments. Ecology, 71, 691-702.

Gliwicz.Z.M. and Pijanowska.J. (1989) The role of predation in zooplankton succession. In Sommer,U. (ed.), Plankton Ecology: Succession in Plankton Communities. Springer Verlag, Berlin, pp. 253-295.

Groeger,A.W., Schram,M.D. and Marzolf,G.R. (1991) Influence of food quality on growth and reproduction in Daphnia. Freshwater Biol., 26, 11-19.

Guisande,C. and Gliwicz,Z.M. (1992) Egg size and clutch size in 2 Daphnia species grown at different food levels. J. Plankton Res., 14, 997-1007.

Gulati,R.D. (1975) A study on the role of herbivorous zooplankton community as primary consumers of phytoplankton in Dutch lakes. Verh. Int. Ver. Limnol., 19, 1202-1210.

Ingle,L., Wood,T.R. and Banta,A.M. (1937) A study of longevity, growth, reproduction and heart rate in Daphnia longispina as influenced by limitations in quanity of food. J. Exp. Zool., 76, 325352.

Lampert,W. (1977) Studies on the carbon balance of Daphnia pulex de Geer as related to environmental conditions. IV. Determination of the 'threshold' concentration as a factor controlling the abundance of zooplankton species. Arch. Hydrobiol., 48(Suppl.), 361-368.

Lampert,W. (1988) The relative importance of food limitation and predation in the seasonal cycle of two Daphnia species. Verh. Int. Ver. Limnol., 23, 713-718.

Lampert,W., Fleckner,W., Rai,H. and Taylor,B.E. (1986) Phytoplankton control by grazing zooplankton: A study on the spring clear-water phase. Limnol. Oceanogr., 31, 478-490.

Larsson,P., Andersen,S., Børsheim, Y., Jakobsen,P. and Johnsen,G. (1985) Individual growth of Daphnia longispina in the summer decline phase of the population. Arch. Hydrobiol. Beih. Ergebn. Limnol., 21, 341-350.

Luecke,C., Vanni,M.J., Magnuson,J.J., Kitchell,J.F. and Jacobson,P.T. (1990) Seasonal regulation of Daphnia populations by planktivorous fish: Implications for the spring clear-water phase. Limnol. Oceanogr., 35, 1718-1733.

Lynch,M. (1977) Fitness and optimal body size in zooplankton populations. Ecology, 58, 763-774.

Lynch,M. (1989) The life history consequences of resource depression in Daphnia pulex. Ecology, 70, 246-256.

Lynch,M. (1992) The life history consequences of resource depression in Ceriodaphnia quadrangula and Daphnia ambigua. Ecology. 73, 1620-1629.

Meyer,J.S., Ingersoll,C.G.. McDonald,L.L. and Boyce,M.S. (1986) Estimating uncertainty in population growth rates: Jackknife vs Bootstrap techniques. Ecology, 67, 1156-1166. 
Moed,J.R. and Hoogveld,H.L. (1982) The algal periodicity in Tjeukemeer during 1968-1978. Hydrobiologia, 95, 223-234.

Mullin,M.M., Fuglister Stewart,E. and Fuglister,F.J. (1975) Ingestion by planktonic grazers as a function of concentration of food. Limnol. Oceanogr., 20, 259-262.

Paloheimo,J.E. (1974) Calculation of instantaneous birth rate. Limnol. Oceanogr., 19, 692-694.

Romanovsky.Y.E. (1984) Prolongation of postembryonic development in experimental and natural cladoceran populations. Int. Rev. Ges. Hydrobiol., 69, 149-157.

Schwenk,K. (1993) Interspecific hybridization in Daphnia: distinction and origin of hybrid matrilines. Mol. Biol. Evol., 10, 1289-1302.

Semenchenko, V.P. (1990) Comparative analysis of reproduction strategies in Cladocera at different food concentrations. $Z h$. Obshch. Biol., 51, 828-835.

Sommer,U., Gliwicz.Z.M., Lampert,W. and Duncan,A. (1986) The PEG model of seasonal succession of planktonic events in fresh waters. Arch. Hydrobiol., 106, 433-471.

Spaak,P. and Hoekstra,J.R. (1994) Life history variation and the coexistence of a Daphnia hybrid with its parental species. Ecology, in press.

Taylor,B.E. (1985) Effects of food limitation on growth and reproduction of Daphnia. Ergebn. Limnol., 21, 285-296.

Tessier,A.J. and Goulden,C.E. (1987) Cladoceran juvenile growth. Limnol. Oceanogr., 32, 680-686.

Threlkeld.S.T. (1979) Estimating cladoceran birth rates: The importance of egg mortality and the egg age distribution. Limnol. Oceanogr., 24, 601-612.

Tillmann,U. and Lampert,W. (1984) Competitive ability of differently sized Daphnia species: an experimental test. J. Freshwater Ecol., 2, 311-323.

Urabe,J. (1988) Effect of food conditions on the net production of Daphnia galeata: Separate assessment of growth and reproduction. Bull. Plankion Soc. Jpn, 35, 159-174.

Urabe,J. (1991) Effect of food concentration on growth, reproduction and survivorship of Bosmina longirostris (Cladocera): an experimental study. Freshwater Biol., 25, 1-8.

Vijverberg.J. (1976) The effect of food quantity and quality on the growth, birth-rate and longevity of Daphnia hyalina Leydig. Hydrobiologia. 51, 99-108.

Vijverberg,J. and Richter,A.F. (1982) Population dynamics and production of Daphnia hyalina Leydig and Daphnia cucullata Sars in Tjeukemeer. Hydrobiologia, 95, 235-259.

Weglenska,T. (1971) The influence of various concentrations of natural food on the development, fecundity and production of planktonic crustacean filtrators. Ekol. Pol., 19, 427-473.

Weider,L.J. and Wolf,H.G. (1991) Life-history variation in a hybrid species complex of Daphnia. Oecologia (Berlin), 87, 506-513.

Wolf.H.G. (1982) A comparison of different electrophoretic techniques for the detection of isoenzymes in single daphnids. Arch. Hydrobiol., 95, 521-531.

Yampolsky.L.Y. and Kalabushkin,B.A. (1991) The components of life-history traits variation in Daphnia magna population. Hydrobiologia, 225, 255-261.

Zaffagnini,F. (1987) Reproduction in Daphnia. Mem. Ist. Ital. Idrobiol, 45, 245-284.

Received on October 30, 1993; accepted on August 9, 1994 